\title{
READINESS OF UNIVERSITY TEACHERS TO PARTICIPATE IN EMPIRICAL DATA EXCHANGE: PILOT STUDY IN UKRAINE
}

\section{aLHA ZHORNOVA, ${ }^{\mathrm{b}}$ OLENA ZHORNOVA, ${ }^{\mathrm{C}} \mathrm{KATERYNA}$ LUT, ${ }^{\mathrm{d}}$ ANASTASIIA ROMANENKO, ${ }^{\mathrm{e}} \mathrm{OKSANA}$ RYNDENKO}

${ }^{A, b}, R$. Glier Kyiv Municipal Academy of Music, Kyiv, L. Tolstoy St, 31, 01032, Ukraine

'Zaporizhzhia Polytechnic National University, Zaporizhzhia, Zhukovs'koho St, 64, 69063, Ukraine

${ }^{d}$ Borys Grinchenko Kyiv University Borys Grinchenko Kyiv University, Kyiv, Bulvarno-Kudriavska St, 18/2, 04053,

Ukraine

${ }^{e}$ Petro Tchaikovsky National Music Academy of Ukraine, Kyiv, Architect Gorodetsky St, 1-3/11, 01001, Ukraine email: ${ }^{a}$ zhornova@ukr.net, ${ }^{b}$ acadmonex@gmail.com, ckateryna@zntu.edu.ua, ${ }^{d}$ rnastyar@gmail.com, eoksanaryndenko@gmail.com

Abstract: The article offers the description of the pilot study results on university

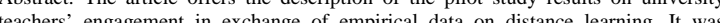
suggest that the was ungested that they have a shaped inenter to exchange, however, the specifics of their effors make it dicte open pincent in data exchange. The research findings can be used in the practice of knowledge the engagement of teachers in the exchange of empirical data.

Keywords: teacher, engagement, empirical data exchange, engagement in the exchange of empirical data.

\section{Introduction}

In many countries, including Ukraine, further digitalization of higher education is recognized as a strategic direction of its development (Digital Education Action Plan 2021-2027; Volungevicienè et al., 2021; Higher Education Development Strategy in Ukraine for 2021-2031). It implies considering both positive and negative aspects of distance learning (Young, 2018), which should be confirmed not only by theoretical but also by empirical evidence. Their lack complicates and makes it almost impossible to understand the features of distance learning and to control it (Alenezi, 2020). These days, it is close to impossible to find open empiricism concerning distance learning in Ukraine, though every teacher has some potentially usable empirical data (hereafter ED). Thus, the relevance of studying teachers' engagement in the ED exchange is explained by the necessity to coordinate the need for free dissemination and reuse of research data on distance learning and individual efforts to share them.

The purpose of the pilot study is to identify the specifics of faculty engagement in the ED exchange. This engagement is most appropriately viewed dispositionally, i.e., as their deliberate decision to make ED available for free dissemination and reuse by other researchers.

We hypothesize that educators do have the intention to make ED available for other researchers to use freely, but the scope of efforts required makes it difficult to integrate their data suitable for analysis into the body of open empiricism.

\section{Literature Review}

Since currently the exchange of ED is the initiative of teachers and goes beyond their job duties, regulated by the relevant normative documents, it is essential to determine how their engagement in such activities affects the university performance. To this end, we compare selected results from heterogeneous studies on intra-organizational knowledge sharing (in terms of approach, research methods, samples, countries, etc.) for a qualitative assessment of engagement in ED sharing. Next, we review works on the role of open empiricism in educational research and practice and then analyze the barriers to the free dissemination of ED and the ways to overcome them.
Studies show that: willingness to share knowledge is positively related to productivity (Jarvenpaa \& Staples, 2001); there is a link between strengthening leadership and knowledge sharing (Srivastava et al., 2006); inducing knowledge sharing leads to a marked increase in organizational effectiveness (Wijk et al., 2008); by supporting and encouraging knowledge sharing, the organization not only achieves competitive advantage but also moves faster towards its goals (Liebowitz, 2001). Despite the fact that the lack of formal job responsibilities for knowledge sharing nullifies its intensity (De Clercq et al., 2013), it is still argued that employee engagement should not be neglected as it might be an opportunity to go beyond established job requirements by taking 'one step up from commitment' (Robinson et al., 2004). In this case, it is important to remember that the employee, taking on additional responsibilities to share knowledge, firstly, expects to be recognized as an expert in some area of professional knowledge (Yuan et al., 2013) and, secondly, makes a decision basing on the value of this knowledge (Pierce, 2012).

As follows from the above, the introduction and encouragement of knowledge sharing have a positive impact both on the functioning of the organization as a whole and on its employees' higher-level understanding of the professional activity.

So, how important is open empiricism in solving educational research problems? Both Ukrainian and foreign scholars working in the field of educational research generally do not refute the rationales for the use of ED. However, they express concerns about both the growing role of empiricism in recent research and the lack of proper attention to the potential of evidence-based pedagogy. Yet, research reliability remains one of the most fundamental issues. In different formulations and contexts, it is connected with the criticism of existing methods (Bridges, 2019; Fim'yar et al., 2019). This highly-cited study is representative in this regard (Glewwe et al., 2011). Having analyzed about 3,000 scientific papers, the authors concluded that the only issues that emerged from these investigations are the factors influencing the quality of education, including the availability of desks in the classroom, teacher's knowledge of the subject, and the absence of a teacher. The authors stated that such results are not novel and are hardly useful to guide the development of future education policy.

As a result, empiricism is now regarded as a public resource, a basis for political decision-making, and an indicator of university performance, in addition to a conventional understanding of it as the source of scientific information.

Examining the difficulties of disseminating open data in general and open empiricism in particular, scholars have pointed to the obvious ways of overcoming them, e.g., by implementing open access policies for research publications. Such a claim was refuted by the study (Savage \& Vickers, 2009) that described an attempt to obtain a set of raw data on medical research and clinical trials: only one of ten corresponding authors provided the required data set, although the request for information explained that the data would be used to test a new hypothesis, not to challenge conclusions. Consequently, the researchers' initial intention to compare levels of data sharing in journals either with or without a clear sharing policy proved unhelpful. Therefore, open access policies are only partially conducive to realizing the potential of free dissemination and reuse of data, without guaranteeing that the difficulties of engaging researchers in these processes are fully overcome. Perhaps the initiative to reconsider how researchers and their academic careers are evaluated in order to ensure a successful transition to open science, supported by universities (Lévy, 2020), will be a key factor in overcoming barriers to ED exchange.

In the academic literature, the analysis of the difficulties and reinforcement of open empiricism is often focused on the place the university occupies in the hierarchy of aggregate research 
visibility of their staff. Faculty members at prestigious universities may have less incentive to share ED because they have sufficient resources at their disposal (D'Este. \& Patel, 2007); they have more opportunities to interact, as the institution itself attracts external stakeholders.

Investigating the potential value of open data as the material for educational use, scholars emphasize (Coughlan, 2020) that they [open data] are rarely developed for educational purposes and are often poorly specified. Moreover, the responsibility for using open data for educational purposes is unclear. In addition, teachers are not sufficiently informed about the differences between open content and copyrighted materials (Rolfe, 2012), open educational resources, or other types of online content (Atenas et al., 2015), which causes misapprehension of their value. It is encouraging to see the potential for various mutually beneficial models of collaboration, shared artifacts, and communication that will increase the visibility of the author and may provide a conceptual framework to support greater use of open access by educators. However, there arise some difficulties: educators are not confident users of digital technologies, they can fail to use them (Zhornova \& Zhornova, 2014), as well as open educational resources or the potential of open pedagogy (Zhornova \& Zhornova, 2017; García-Holgado et al., 2020).

Teachers' support for open data, in general, and open empiricism, in particular, is associated with increased awareness of stakeholders about their achievements, additional opportunities to promote their research and enter international scientific communities. However, the lack of knowledge about data dissemination and reuse, as well as the low level of digital literacy (Zhornova? 2013), have a negative impact on the state of open empiricism.

Thus, based on the results of the scientific literature review, we can conclude that:

- the engagement of educators in ED exchange will not have negative consequences for the university;

- overcoming the barriers to ED exchange is related to increasing teachers' understanding of the process and methods of open data dissemination and reuse.

\section{Materials and methods}

The empirical study of teachers' engagement in ED exchange consisted of two stages: the first stage was to identify the meaningful constructs of engagement in ED exchange through interviews, based on which a questionnaire was then created: and the second stage was to identify its inherent features through questionnaires.

\section{Interview}

In September 2020, we conducted unstructured interviews with educators at Ukrainian universities. All respondents had experience in conducting psychological and pedagogical empirical research.

Five faculty members were interviewed, including women (4) and a man (1); doctors of science, professors (2), candidates of science, associate professors (2), a senior lecturer (1); aged from 38 to 62 years old. All interviews were conducted in person and lasted 20 to 35 minutes. During the interviews, all respondents demonstrated interest in the research. To guide respondents' reflections, we asked them to express their opinion on the engagement of educators in ED exchange and determine the criteria to discover their intentions to share. Our synthesis of the information provided resulted in the identification of the main meaningful constructs.

The questionnaire survey was conducted in November 2020, data being collected anonymously. All interviewees were informed of the purpose of the study.

\section{Sample}

Among 44 respondents who completed the questionnaire, most of them were women (31). Regarding the age: under 35 years old (three respondents), from 36 to 55 (21), over 55 (20). Work experience: respondents, working in higher education for up to five years (2), 6 to 20 years (14), and more than 20 years (28). Three participants do not have a scientific degree, 23 are candidates of science, and 18 have doctoral degrees; 36 respondents have academic titles: professors (13) and associate professors, senior researchers, or senior research fellows (23). Two respondents are senior faculty members, five are faculty members; there is an almost equal number of professors and assistant professors (18 and 19, respectively).

To analyze the obtained data, we used:

- content analysis to identify the characteristics of the engagement;

- context analysis to specify and unify the meaningful constructs of engagement in the ED exchange;

- contrastive and comparative analysis to discover similarities and differences in teachers' engagement in ED sharing;

- generalization to establish common and specific features in the identified varieties of ED exchange engagement;

- grouping to combine the identified varieties of engagement;

- methods of mathematical statistics to assess the significance of engagement in ED exchange.

\section{Findings and discussions}

\section{The first stage of the empirical research}

According to respondents, ED exchange among educators has not become usual practice. One of the possible reasons is that data sharing is not their priority.

I believe that a small number of colleagues participate in data sharing. Certainly, for some people it's important, but there are probably some who don't care about it at all.

Meanwhile, views on the popularity of empirical research on distance learning divide respondents into two groups: those who argue that it is a common practice (Everyone or almost everyone collects ED. How can you teach at a university and not try to scientifically explain certain learning outcomes?), and those who think that this is rather an exception and that only a small number of colleagues work on it (Not all colleagues collect empirical data. I don't think many people collect data.)

The importance of ED exchange for the development of science is not questioned (Of course, I agree that the exchange of data allows us to talk about the quality of the research conducted. I hope we will see new laws appear in pedagogy instead of conclusions generally useless for science). As a result, the reasons for non-participation in ED exchange are based on the following: differences in scientific interests (Shall we share the information we collect? It is not always easy to decide. What interests me is not always interesting for others. You also need to be able to present the data appropriately); on the gradual effort (Know how to make data available, and understand that without it there can be no exchange - this should be the first thing to talk about. Only after that we can make the first steps to data sharing...).

However, considering the efforts spent on collecting ED as a loss of irretrievable resources (especially time and health) weakens the desire to share available data (Many researchers conduct pedagogical experiments, especially for their dissertation. But not all are ready to share the data collected before defending their thesis. And then you wonder if it is worth going back to what was done... After all, you can't return the eyesight or the time"; "There are so many new concepts, that doubts only increase... To revise everything again, to redo... So much time! In addition, sitting in front of the computer...). 
When discussing data exchange, respondents describe some of its benefits and challenges based solely on their own experience ("Sometimes asking colleagues for data is the fastest and most effective way to share. Certainly, you will provide your data in return, if needed. So, all that we have is cooperation and mutual support". "It is impossible to attach your ED to the article in a printed edition of a scientific journal. That is why the article is published in a journal, but ED must be deposited elsewhere"). Understanding the limitations of their experience, respondents plan to overcome them either with the help of their colleagues ( $I$ would gladly exchange data. But where shall I send them? Where are they stored? I have to ask my colleagues, they might have a better understanding of it. No one said anything about that, though) or on their own (Did you try to upload the data? I tried several times. What was the outcome? None!!! It wasn't that the data were not properly formatted. It didn't even get that far. Everything stopped at some account requirements, which I never understood. I keep trying.) It should be mentioned that the respondents tried to explain and not justify their insignificant contribution to ED exchange. (Sometimes, it is so difficult to find necessary materials that you lose hope. If you understand that research cannot be isolated, that all findings have to be combined into collections or other forms, then this is an indication of your participation in the data exchange"; "We are writing and publishing, writing and publishing... And we do not even raise the question of clarifying, comparing, complementing what has already been done. We just do not know where and how to look).

In general, the respondents' reasoning about faculty engagement in ED exchange can be grouped according to the following statements:

- teachers are more likely to have the intentions to share and reuse ED;

- most faculty members have at least one set of ED that are of interest to other educators;

- educators share ED in various ways: such data may be uploaded to special platforms, published in journals dedicated to data, sent to colleagues at their request, etc;

- educators' failure to understand the significance of each stage of data dissemination makes it difficult to share ED.

Thus, the results of the conducted content and context analyses showed that teachers could be engaged in ED exchange in different ways: a) they recognize the relevance of ED exchange; b) have experience or at least made some attempts to share data; c) have some understanding of the process of data dissemination.

\section{The second stage of the study}

Based on these findings, a questionnaire "Empirical Data Sharing" was developed to determine the following:

1. Shaped intention to share ED.

2. Consistent application of ED exchange methods.

3. Conscious assistance to data sharing.

The first three questions were designed to discover the shaped intention to share ED. The first question focused on the relevance of ED sharing, the second - on the frequency of ED sharing among university teachers, and the third - on the criteria for selecting ED to share. While determining the relevance of the ED exchange, we used a 5-point Likert scale (very important, important, undecided, slightly important, unimportant) to measure the importance of the exchange effort. Such a scale was also used to discover the frequency of data sharing and its availability (definitely have, probably have, do not know, probably do not have, definitely do not have). The respondents' choice of one of the suggested criteria for selecting ED to share clarifies if the effort is directed at sharing. Thus, the answer "data that other researchers might need" is the most indicative of this orientation, while "do not know" indicates the absence of this orientation. Other responses only point to insufficient focus on the ED exchange.
Consistent application of ED exchange methods is revealed through consistent approbation. For this purpose, the role of the most acceptable ED exchange method for a teacher is correlated with that of other methods.

The sixth question clarifies the respondents' awareness of the distribution logic, i.e., whether they know what skills they need to master in order to exchange ED and whether they are capable of estimating their significance. The list of skills is based on the so-called five-star rating of engagement in the dissemination of open data 'How many stars do you have?' by Tim Berners-Lee (5-star Open Data plan).

The following are the questions of the questionnaire:

1. Rate the importance of sharing empirical data on the characteristics of distance learning.

2. Do your colleagues or other researchers have empirical data on the characteristics of distance learning?

3. Which of the empirical data you have collected are to be exchanged?

4. What is the most acceptable way of sharing empirical data for you at the moment?

5. Rate how important it is to: a) share empirical data informally (e.g., at the request of colleagues); b) upload empirical data as an appendix to publications in journals with clear data sharing policies; c) deposit empirical data in thematic, institutional, and multidisciplinary data repositories; d) post empirical data to corporate (university) sites; f) publish ED in special data journals.

6. How important is it for a university teacher to be able to: a) use an open license; b) structure empirical data; c) use nonproprietary formats; d) use URLs and other codes; f) link data.

The results of the survey are published at Mendeley.data (Zhornova \& Zhornova, 2021). Their analysis provides answers to three main questions: 1 . Can it be claimed that the educators have formed an intention to share ED? 2. To what extent are educators' efforts to share ED coordinated with each other? 3. Are there reasons to believe that educators are familiar with the processes of ED dissemination and reuse? Let us consider them one by one.

Can it be claimed that the educators have formed an intention to share ED?

None of the respondents questioned the importance of ED exchange (mode 27). However, the respondents' are not sure whether their colleagues have ED or not: only 19 times the answer probably have was chosen (mode 19). The fact that none of them claim that colleagues do not have ED is encouraging.

As for the criteria for selecting ED to share, the answers were as follows: the majority of those surveyed (26) agreed on the response data that has some value; three respondents were undecided about the criteria for selecting ED to share, twice as many think that all the ED they have collected are worth exchanging. It should be noted that none of the respondents thinks, that their ED cannot be shared (Zhornova et al., 2021).

As we can see, the respondents generally understand the importance of ED sharing, but they are not so sure whether their colleagues have ED worth sharing or whether they are ready to share. Thus, every fourth does not know at all whether colleagues have ED or not, and only every fifth (20\% or 9) showed some understanding of the essence of data exchange (by choosing the option the data that can be useful for other researchers while answering the question about the type of ED to be shared). In general, the results suggest that the respondents have formed the intention to share ED.

To what extent are educators' efforts to share ED coordinated with each other?

The three most acceptable ways include posting on university websites (27\%), uploading as an attachment to a publication 
(27\%), and depositing in a data repository (23\%). The least preferred ways include publishing in special data journals (9\%) and informal sharing (14\%). We can observe the following efforts: a) to maintain data sharing within universities, which is consistent with the statement of Blagov (Blagov et al., 2017), b) to reserve the proprietary right to be the first to analyze the collected ED, and c) store the data in a place designated for this purpose.

The fact that only $14 \%$ prefer to share ED informally proves that it is not common among university teachers. It can be explained both by the lack of demand and by a focus on a higher level of exchange to create a larger platform for sharing. We tend to believe that the latter is more consistent with the results described above.

In the responses to the question concerning the role of ED exchange methods, the central tendency in determining their importance is clear: mode - response important. Below is the number/percentage of options for each method: appendix to the publication: 24/54.5\% ; data deposition in repositories: 26/59.1\%; posting empirical data to corporate (university) sites: 24/54.5\%; publishing in special data journals: $25 / 56.8 \%$; informal data sharing: $21 / 47.7 \%$.

As you can see, under half of the respondents consider informal sharing important, which makes it the least preferable method. It gives grounds to declare that, despite significant differences in what is considered the most acceptable ways for data exchange, a consistent approbation of them has been worked out.

So what kinds of configurations of consistent application of exchange methods do the respondents prefer? By the configuration of consistent application, we understand the compatibility of the most acceptable method with other methods of ED exchange.

We noticed that:

- The most common configuration, which is observed 18 times: the most acceptable for the respondent method is as important as the others (at least one more option is rated important). We call this type co-oriented efforts;

- The configuration that follows was chosen 13 times: the most acceptable method is the most important of all (only the most acceptable method is considered very important). We call this type focused effort.

There is also a configuration observed seven times, which we call extremely important efforts: the most acceptable method is not the only one to be defined as very important.

There are also some individual configurations: a) the most acceptable method is the only one whose role can be evaluated; b) its role cannot be evaluated at all; c) the role of other methods is important and that of the most acceptable one is unimportant; d) the role of the most acceptable method is not different from that of the other methods considered less important or unimportant.

In general, configurations with a negative assessment of the role of the most acceptable method are incomparably less common than configurations with a positive one. The latter makes up almost $91 \%$ of the answers.

Considering the information mentioned above, it is justified to talk about the prevalence of consistent approbation of different methods of ED exchange. However, any configuration is timeconsuming.

Are there reasons to believe that educators are familiar with the processes of ED dissemination and reuse?

Since understanding the logic of data dissemination involves the ability to assess the significance of the skills necessary for this process, we analyze the following: a) two levels of assistance: support and rejection; b) two degrees of confidence: full and partial. They are measured on an interval scale of significance (unimportant
- probably unimportant - probably important - very important), because it is assumed that: a) the answers probably important and probably unimportant are the same distance from very important and unimportant, and b) the same distance is between probably important and probably unimportant. Thus, each of the proposed significance ratings is equidistant from the neighboring one.

The spread and distribution of the skill significance ratings are shown in Figure 1 and (Zhornova et al., 2021) The analysis of the results showed that: each of the skills received the highest score (very important), only the ability to use non-proprietary formats rated as the lowest (unimportant). The biggest range of opinions was expressed regarding the ability to use non-proprietary formats, the lowest - to structure ED; the average is in the range from slightly above probably important to very important (Figure 1).

Figure 1. Range of opinions (1- unimportant; 2- probably unimportant; 3 - probably important; 4 - very important)

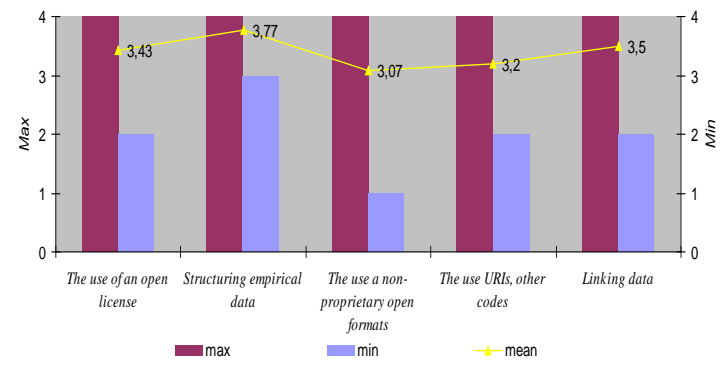

We should note the asymmetry in the distribution of the significance ratings for each skill. Thus, positive asymmetry, i.e., when lower values of a feature are more common in the distribution, is observed for such skills as using codes and linking data, while negative asymmetry, with higher values of importance, is observed for the others (Zhornova et al., 2021).

The predominance of mean or close to mean values is characteristic for the skills to use non-proprietary formats and apply URL and other codes (have a positive kurtosis), while for other skills - the kurtosis is negative, indicating the predominance of extreme values of significance.

The data obtained (Zhornova et al., 2021) reveal an unanimity in the respondents' views on the importance of each stage of data dissemination. Thus, the response unimportant is found only once (out of 220 observations); probable and definite assessments are almost equally represented: $54 \%$ and $46 \%$, respectively; the support of the data dissemination process at each of the stages was observed in 208 responses, which makes about 95\%.

We identified only two of the four possible options for conscious assistance in our study, namely strong and mild support of the logic of data dissemination (Figure 2).

Figure 2. Configurations of conscious assistance

\begin{tabular}{|c|c|c|}
\hline & $\begin{array}{l}\text { Rejection } \\
\text { Complete misunderstanding } \\
\text { of the data dissemination } \\
\text { logic } \\
\text { All responses are negative } \\
\mathbf{0}\end{array}$ & $\begin{array}{l}\text { Support } \\
\text { Complete understanding of } \\
\text { the data dissemination } \\
\text { logic } \\
\text { All responses are positive } \\
\qquad \mathbf{1 8}\end{array}$ \\
\hline : & $\begin{array}{l}\text { Mild rejection } \\
\text { Partial misunderstanding of } \\
\text { the data dissemination logic } \\
\text { Most responses are } \\
\text { negative, doubts about } \\
\text { significance prevailing, } \\
\text { positive estimation } \\
\mathbf{0}\end{array}$ & $\begin{array}{l}\text { Mild support } \\
\text { Partial understanding of the } \\
\text { data dissemination logic } \\
\text { Most responses are } \\
\text { positive, doubts about } \\
\text { significance prevailing, } \\
\text { negative estimation } \\
26\end{array}$ \\
\hline & & \\
\hline
\end{tabular}


It is likely that there are causes that influence the level of support of all skills, but have little or no effect on the level of confidence. Since examining such causal relationships is beyond the scope of this study, we focused on establishing correlations between the levels of significance of different skills, as well as their strength and direction. We believe that the assistance to ED exchange is confirmed by significant two-way correlations (desirable value is 0.05 , sufficient - 0.01) among all significance levels of all the studied skills.

Still, the results (Table 1 ) showed only 6 correlations, which makes, however, more than a half $(60 \%)$. The analysis was performed using statistical packages SPSS 20.0.

Table 1: Correlation analysis results (Spearman's $\rho$ )

\begin{tabular}{|c|c|c|c|c|c|}
\hline & 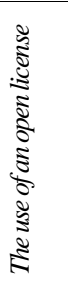 & 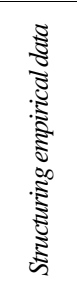 & 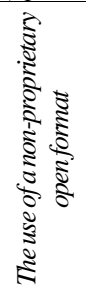 & 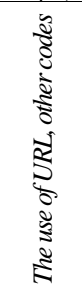 & 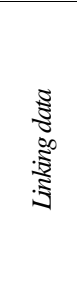 \\
\hline $\begin{array}{l}\text { The use of an } \\
\text { open license }\end{array}$ & 1.000 & $.367 *$ & $.323^{*}$ & .172 & .064 \\
\hline $\begin{array}{c}\text { Structuring } \\
\text { empirical data }\end{array}$ & $.367^{*}$ & 1.000 & .240 & $.330 *$ & $.433^{* *}$ \\
\hline $\begin{array}{c}\text { The use of a } \\
\text { non-proprietary } \\
\text { open format }\end{array}$ & $.323^{*}$ & .240 & 1.000 & $.384^{* *}$ & .275 \\
\hline $\begin{array}{l}\text { The use of URL } \\
\text { and other codes }\end{array}$ & .172 & $.330 *$ & $.384^{* *}$ & 1.000 & $.564^{* *}$ \\
\hline Linking data & .064 & $.433 * *$ & .275 & $.564 * *$ & 1.000 \\
\hline
\end{tabular}

*. Correlation significant at the 0,05 level (2-tailed)

**. Correlation significant at the 0,01 level (2-tailed).

As we can see, the correlation is not random between the assessment of the significance: using open license and structuring data, using non-proprietary formats and open license, structuring data and coding them; linking data and structuring them; using non-proprietary formats, using URL and other codes; using URL and other codes and linking data.

None of the significance assessments of skills is fully related to those of the other skills, and no skill is completely isolated in terms of its significance assessment. Structuring and coding have the greatest number of associations (3), while the others have two.

Thus, we can state that the teachers are familiar with the process of open data sharing, but to further improve the conscious assistance they need to increase their understanding of its logic and to improve their existing experience in using open license and non-proprietary formats, data structuring, data coordination, and coding.

\section{Conclusion, limitations and further development}

The introduction of the quarantine became a "litmus paper", which showed the lack of exchange of primary research data on distance learning and actualized the problem of teachers' engagement in ED exchange.

The findings of the pilot study of the engagement, considered dispositionally, demonstrate that at this stage we have reached a meaningful understanding of its manifestations through a) shaped intention to share ED, b) consistent application of its methods, and c) conscious assistance to it.

We have revealed that teachers: formed the intention to share ED; despite significant differences in the most acceptable methods of ED exchange, developed their consistent approbation. Different types of configurations of concerted efforts, i.e. co-oriented, focused, and extremely important effort, which are similar in that they are time-consuming.
The teachers are unanimous about the significance of the stages of data dissemination: they are familiar with the process of disseminating open data, but they need to increase their understanding of its logic to further improve their conscious assistance.

It suggests that there is a gap in the chain of efforts to make ED available for free dissemination and reuse by other researchers, namely that the effort spent on collecting ED does not translate into efforts to fully integrate them into the body of scientific knowledge.

Therefore, faculty members' engagement in ED sharing can be regarded as an intention to promote ED dissemination rather than to strengthen and improve existing ED sharing practices.

University teachers need to make a transition from collecting ED to participating in the formation of a database of digital scientific data on distance learning. Certainly, it involves understanding the responsibility for the selection of ED to be included in the stream of knowledge on distance learning, as well as the willingness to take responsibility for it.

Most likely, the post-pandemic future of higher education will involve a new round of evidence-based pedagogy, when it will become impossible to propose and evaluate alternative solutions to learning in higher education without reliance on open primary data. However, even today, every teacher's redefinition of their role in such a future must begin now by improving their engagement in ED exchange.

Since the conducted research has focused on examining engagement in sharing data on the characteristics of distance learning, further research needs to be directed toward understanding the following:

- to what extent can the findings be extrapolated to other learning problems and other types and kinds of data;

- what are the implications of teachers' engagement in ED exchange in the long term.

The data for this study were collected from a small number of respondents, representing not all higher education institutions in Ukraine. Therefore, it is likely that intentions of teachers from other universities will be different from those presented in this paper.

\section{Literature:}

1. 5-star Open Data plan. https://5stardata.info/en/

2. Alenezi, A. M. (2020). The relationship of students' emotional intelligence and the level of their readiness for online education: A contextual study on the example of university training in Saudi Arabia. The Education and Science Journal. 4 (22), 89-109. DOI: 10.17853/1994-5639-2020-4-89-109

3. Atenas, J., Havermann, L. \& Priego, E. (2015). Open data as open educational resources: Towards transversal skills and global citizenship. Open Praxis. 7(4), 377-389. https://doi.org /10.5944/openpraxis.7.4.233

4. Blagov, E.Yu. \& Pleshkova, A.Yu. (2017). Barriers to knowledge sharing in administrative units within higher education institutions. Journal of Creative Economy, 11(3), 285302. DOI:10.18334/ce.11.3.37708 (in Rus.)

5. Bridges, D. (2019). 'Rigour', 'discipline' and the 'systematic' in educational research - and why they matter. European Educational Research Journal. 18 (5), 499-512. DOI:10.1177/1474904119868558

6. Coughlan, T. (2020). The use of open data as a material for learning. Education Tech Research Dev. 68, 383-411. https://doi.org/10.1007/s11423-019-09706-y

7. D'Este, P. \& Patel, P. (2007). University-industry linkages in the UK: What are the factors underlying the variety of interactions with industry? Research Policy, 36(9), 1295-1313. https://www.sciencedirect.com/science/article/abs/pii/S0048733 307001199

8. De Clercq, D., Dimov, D. \& Thongpapanl, N. (2013). Organizational social capital, formalization, and internal 
knowledge sharing in entrepreneurial orientation formation. Entrepreneurship: Theory \& Practice, 3, 505-537. doi.org/10. 1111/etap.12021

9. Digital Education Action Plan 2021-2027. https://ec.euro pa.eu/education/sites/default/files/document-library-docs/deapcommunication-sept2020_en.pdf

10. Fim'yar, O, Kushnir, I. \& Vitrukh, M. (2019). Understanding Ukrainian pedagogical sciences through textbook analysis of four 'Pedagogy' textbooks. European Educational Research Journal. 18(5), 576-595. DOI: 10.1177/14749041 19866516

11. García-Holgado, A., García-Peñalvo, F. J., VázquezIngelmo, A., Burgos, D., Nascimbeni, F., Padilla Zea, N., Higuera, C., Hvarchilkova, D., Teixeira, A., Ehlers, U. D. \& Brunton, J. (2020). Promoting open education through gamification open game / Handbook of successful open teaching practices. OpenGame Consortium. https://opengame-proje ct.eu/wp-content/uploads/2020/07/OpenGame-IO1-Handbook OfSuccesfulOpenPractices.pdf

12. Glewwe, P., Hanushek, E., Humpage, S. \& Ravina, R. (2011). School resources and educational outcomes in developing countries: A review of the literature from 1990 to 2010. NBER Working Paper. https://www.nber.org/syste m/files/working_papers/w17554/w17554.pdf

13. Higher Education Development Strategy in Ukraine for 2021-2031. http://www.reform.org.ua/proj_edu_strategy_20212031.pdf (in Ukr.)

14. Jarvenpaa, S. \& Staples, S. (2001). Exploring Perceptions of Organizational Ownership of Information and Expertise. Journal of Management Information Systems, 18(1), 151-183. www.jstor.org/stable/40398520

15. Lévy, P. (2020). The COVID-19 pandemic is pushing open access forwards. University World News 24 October. https://w ww.universityworldnews.com/page.php?page=UW_Main

16. Liebowitz, J. (2001). Knowledge management: learning from knowledge engineering. DOI:10.1201/9781420041125

17. Pierce, L. (2012). Organizational structure and the limits of knowledge sharing: Incentive conflict and agency in car leasing. Management Science, 6, 1106-1121. https://doi.org/10.128 7/mnsc. 1110.1472

18. Robinson, D., Perryman, S. \& Hayday, S. (2004). The Drivers of Employee Engagement Report 408. Institute for Employment Studies. https://www.employment-studies.co.uk/ system/files/resources/files/408.pdf

19. Rolfe, V. (2012). Open Educational Resources: staff attitudes and awareness. Research in Learning Technology, 20, 1-13. https://doi.org/10.3402/rlt.v20i0/14395

20. Savage, C. \& Vickers, A. (2009). Empirical study of data sharing by authors publishing in PLoS Journals. PLOS ONE, 4(9), e7078. https://doi.org/10.1371/journal.pone.0007078

21. Srivastava, A., Bartol, K. \& Locke, E. (2006). Empowering leadership in management teams: effects on knowledge sharing, efficacy, and performance. Academy of Management Journal. 49, 1239-1251. DOI:10.5465/AMJ.2006.23478718

22. Volungevicienè, A., Brown, M., Greenspon, R., Gaebel, M. \& Morrisroe, A. (2021). Developing a high performance digital education ecosystem: Institutional self-assessment instruments. https://www.eua.eu/downloads/publications/digi-he\%20desk \%20research\%20report.pdf

23. Wijk, R., Jansen. J. \& Lyles, M. (2008). Inter- and intraorganizational knowledge transfer: a meta-analytic review and assessment of its antecedents and consequences. Journal of Management Studies. DOI:45.830-853. 10.1111/j.14676486.2008.00771.x

24. Young, S. (2018). From Disruption to Innovation: Thoughts on The Future of MOOCs. Educational Studies Moscow, 4. 2143. https://doi.org/10.17323/1814-9545-2018-4-21-43

25. Yuan, Y. C., Zhao, X., Liao Q. \& Chi, Ch. (2013). The use of different information and communication technologies to support knowledge sharing in organizations: from e-mail to micro-blogging. Journal of the American Society for Information Science and Technology. 64 (8). DOI:64. 10.1002/asi.22863 26. Zhornova, O. (2013). Multimedia personality competence as a socio-psychological basis for the simultaneous growth of its sociality and individuality. Scientific studies in social and psychological psychology, 33, 87-97. (in Ukr.).
27. Zhornova, O. \& Zhornova, O. (2014). What are the prospects of e-learning in Ukraine? Pilot study of a lecturer's endeavor to promote e-learning. DisCo 2014: New media literacy education from pupils to lifelonglearning. 184-196. https://www.academia.edu/31677011/9th_conference_DisCo_re ader_New_media_literacy_education_from_pupils_to_lifelong_l earning_pdf

28. Zhornova, O. \& Zhornova, O. (2017). The main challenges to open educational resources in Ukrainian context. Disco: Open education as a way to a knowledge society. 93-116. https://publons.com/journal/840986/disco-open-education-as-away-to-a-knowledge-socie/

29. Zhornova, O. \& Zhornova, O. (2021). Sharing empirical data. Mendeley Data, V1. DOI: 10.17632/64dp6kpk7c.1

30. Zhornova, O., Zhornova, O. \& Lut, K. (2021). Empirical data sharing: visualization of survey results. Mendeley Data, V1, doi: 10.17632/kbfbrkrmr7.1

\section{Primary Paper Section: A}

Secondary Paper Section: M 